
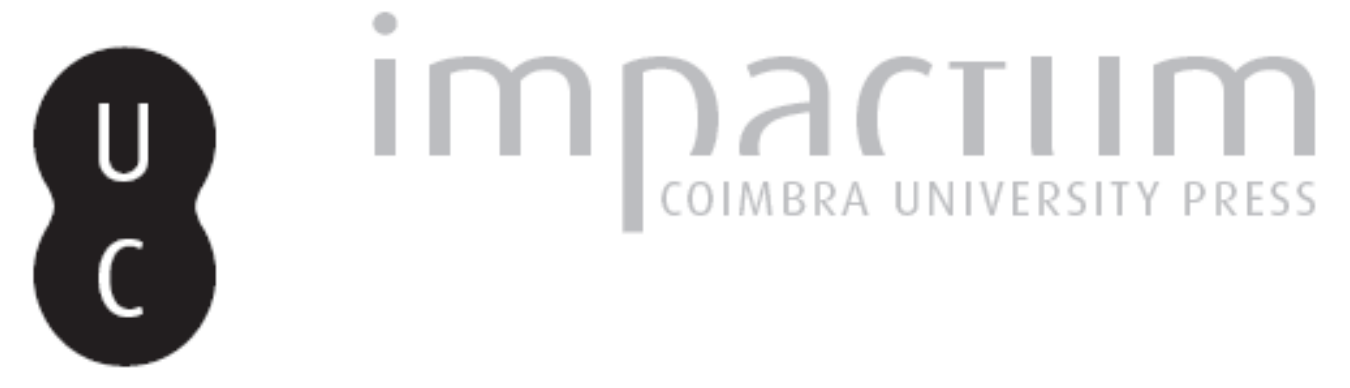

\title{
Futurismo e futurismos em Portugal
}

\author{
Autor(es): $\quad$ Marnoto, Rita
}

Publicado por: Imprensa da Universidade de Coimbra

URL persistente:

URI:http://hdl.handle.net/10316.2/42574

DOI:

DOl:https://doi.org/10.14195/0870-8584_4_5

Accessed : $\quad$ 26-Apr-2023 16:10:49

A navegação consulta e descarregamento dos títulos inseridos nas Bibliotecas Digitais UC Digitalis, UC Pombalina e UC Impactum, pressupõem a aceitação plena e sem reservas dos Termos e Condições de Uso destas Bibliotecas Digitais, disponíveis em https://digitalis.uc.pt/pt-pt/termos.

Conforme exposto nos referidos Termos e Condições de Uso, o descarregamento de títulos de acesso restrito requer uma licença válida de autorização devendo o utilizador aceder ao(s) documento(s) a partir de um endereço de IP da instituição detentora da supramencionada licença.

Ao utilizador é apenas permitido o descarregamento para uso pessoal, pelo que o emprego do(s) título(s) descarregado(s) para outro fim, designadamente comercial, carece de autorização do respetivo autor ou editor da obra.

Na medida em que todas as obras da UC Digitalis se encontram protegidas pelo Código do Direito de Autor e Direitos Conexos e demais legislação aplicável, toda a cópia, parcial ou total, deste documento, nos casos em que é legalmente admitida, deverá conter ou fazer-se acompanhar por este aviso.

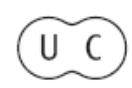




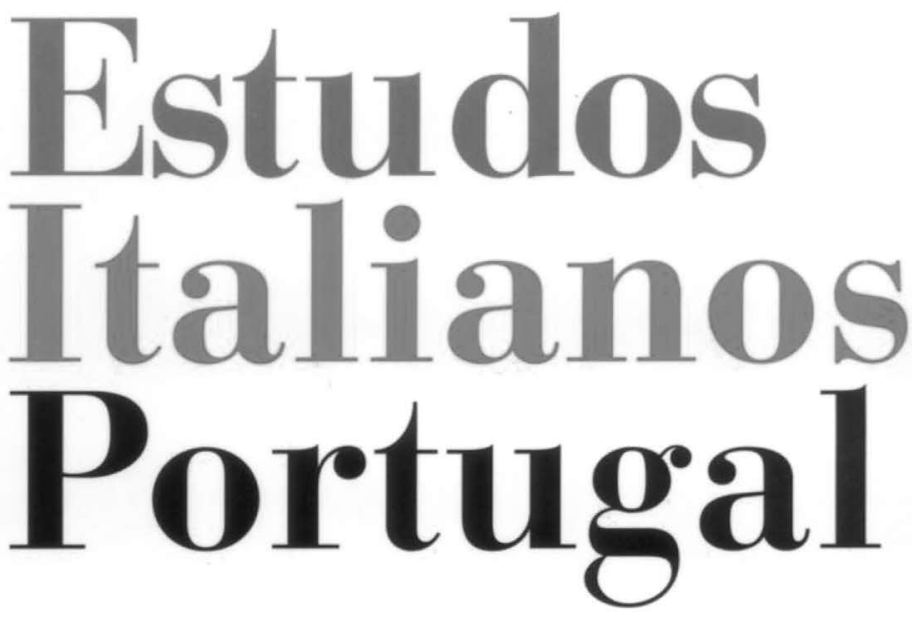

Instituto

Italiano

de Cultura

de Lisboa

Nova Série

$\mathbf{N}^{\mathbf{0}} 4$.

2009 


\title{
FUTURISMO E FUTURISMOS EM PORTUGAL
}

\author{
Rita Marnoto*
}

\begin{abstract}
As Celebrações do Centenário do Manifesto de fundação do Futurismo, editado em $1909^{1}$, têm-se vindo a revelar, para além da efeméride, proficua oportunidade para a elaboração daquele balanço crítico, distanciado e rigoroso, que há muito urgia levar a cabo acerca da vanguarda italiana.
\end{abstract}

* Professora da Faculdade de Letras da Universidade de Coimbra e Directora do respectivo Instituto de Estudos Italianos, dedica-se ao estudo da literatura italiana, da literatura portuguesa e das relações entre as duas literaturas, com referência a vários períodos e autores. Este texto é a versão reduzida, em português, de uma conferência realizada na Universidade de Princeton.

1 Na realidade, em finais de 1908, apesar de o grande veículo da sua divulgação internacional ter sido Le Figaro de 20 de Fevereiro de 1909. Já anteriormente tinha sido editado, em versão integral, como texto de abertura de dois livros publicados em 1908: Le ranocchie turchine de Cavacchioli e a antologia Enquête internationale sur le vers libre. Além disso, Marinetti mandara imprimir, em finais desse mesmo ano, milhares folhas volantes com os seus pontos programáticos, impressas a azul, com uma tiragem em italiano e outra em francês. Prepara, entretanto, a sua publicação no número da revista Poesia de Dezembro de 1908-Janeiro 1909, onde acabará por não sair, em circunstâncias que se prendem com o terramoto de Messina. Mas a partir do momento em que os manifestos começam a ser distribuídos, no final de Janeiro, logo é referido e publicado, integral ou parcialmente, em vários jornais italianos, com destaque para a edição integral que dele é feita por La Gazetta d'Emilia, de Bolonha, a 5 de Fevereiro. Vd. Giovanni Lista, "Genesi e analisi del Manifesto del Futurismo di Filippo Tommaso Marinetti, 1908-1909", in Futurismo Avanguardia Avanguardie, a cura di Didier Ottinger, Parigi, Centre Georges Pompidou, Milano, 5 Continents Éditions, 2009, pp. 78-83.

Est.Ital.Port., n.s., 4, 2009: 61-75 
Saliento dois aspectos que, não sendo propriamente novidade, nem sempre mereceram o devido relevo, pois assinalam percursos de investigação que, em tantas das suas vertentes, aguardam ser explorados. O primeiro, diz respeito ao reconhecimento do Futurismo italiano como vanguarda que serviu de referência, de uma forma ou de outra, a todos os movimentos de vanguarda que se lhe seguiram. O segundo, diz respeito à escala da sua irradiação, que é múltipla, numa abrangência dotada de contornos planetários. $\mathrm{O}$ próprio facto de se tratar da primeira vanguarda histórica potenciou essa projecção por latitudes e longitudes substancialmente diferenciadas, o que implica substratos literários, culturais e artísticos muito vários, numa proposta de renovação global de costumes e experiências de vida. A vastidão dessa articulação de factores, com as suas variáveis, não pode deixar de ser directamente proporcional à multiplicidade dos resultados decorrentes da sua recepção.

Aliás, a divulgação do Futurismo era também propiciada pelo dinamismo e pelo talento publicitário de Marinetti, que viajava pelos quatro cantos do mundo. Nascido em Alexandria do Egipto, formado em França e em Itália, residente em Milão e depois em Roma, era um cosmopolita, faceta da qual soube tirar o melhor partido para dar a conhecer o movimento.

Possuía plena consciência do potencial contido na articulação entre o carácter matricial da vanguarda que liderava e a autonomia dos vários movimentos futuristas. Em $A l$ di là del comunismo, de 1920, escreve em letra sonante ${ }^{2}$

Tutti i Futurismi del mondo sono figli del Futurismo italiano, creato da noi a Milano dodici anni fa. Tutti i movimenti futuristi sono però autonomi. Ogni popolo aveva o ha ancora un suo passatismo da rovesciare.

2 Al di là del comunismo (1920), F. T. Marinetti, Teoria e invenzione futurista, prefazione di Aldo Palazzeschi, introduzione, testo e note di Luciano De Maria, Milano, Mondadori, 1968 [1. ${ }^{a}$ ed.], p. 413; vd. também a nota da p. CVII. 
O potencial desta articulação nem sempre mereceu relevo, no plano crítico-literário. Al di là del comunismo fora originariamente escrito na prisão de San Vittore, onde Marinetti estivera encarcerado, em 1919, juntamente com Mussolini e com outros participantes no movimento armado que contestara a vitória eleitoral socialista. $\mathrm{O}$ direccionamento da sua leitura em sentido ideológico deixou na sombra, porém, muitos aspectos do horizonte internacional visado por um manifesto que tem por incipit, Ai futuristi francesi, spagnoli, russi, ungheresi, rumeni, giapponesi.

Foi sobre o pano de fundo da teoria dos códigos que, a partir da década de Setenta, essa articulação começou a ser verdadeiramente explorada. Fica condensada na correlação entre Futurismo, no singular, e Futurismos, no plural, que serve de ponto de partida ao presente estudo. Les Futurismes foi título dos dois números que a revista Europe dedicou ao tema, em 19753. "Il n'y a pas un ton, mais des tonalités", escreve Charles Dobzynski no editorial. Essa perspectiva foi depois potenciada e documentada pela exposição no Palazzo Grassi de Veneza, Futurismo e Futurismi, de 1986. A variedade de folhetos, edições e obras de arte futuristas nela coligidas confrontou o olhar do visitante com um acervo documental de dimensões impressionantes ${ }^{4}$. A fecundidade dessa lei-

3 Ano 53, 551, 552, 1975. Cit. de "À l'assaut du siècle", 551, p. 5.

${ }^{4}$ Vd. Futurismo e Futurismi. Catalogo della mostra, Venezia, Palazzo Grassi, a cura di Pontus Hulten, Milano, Bompiani, 1986, 1992. A importância crítica dessa perspectiva múltipla e abrangente acerca do Futurismo é ilustrada pela série de exposições que, de diferentes modos, nela se revê, desde Futurismo e meridione, de 1996, no Palazzo Reale de Nápoles (catálogo, Futurismo e meridione, a cura di Enrico Crispolti, Napoli, Regione Campania, Electa, 1996), até às actuais Futurismo 1909-2009 Velocità + Arte + Azione, Milão, Palazzo Reale (catálogo Skira); Futurismo Avanguardia Avanguardie, Roma, Scuderie del Quirinale; Paris, Centre Georges Pompidou; Londres, Tate Modern (catálogo Centre Georges Pompidou, 5 Continents Éditions); Il futuro del Futurismo. Dalla "rivoluzione italiana” all'arte contemporanea, Bergamo, GAMeC (catálogo Electa) ou Italics. Arte italiana fra tradizione e rivoluzione, 1968-2008, Veneza, Palazzo Grassi (catálogo 
tura reafirma-se, na actualidade, enquanto fio condutor que liga as várias manifestações organizadas em Itália, por ocasião do centenário futurista.

A linha de leitura do Futurismo/s português que apresento propõe-se dar uma visão de conjunto, em traços necessariamente sintéticos, da sua projecção, de forma a contemplar a irradiação do movimento por vários espaços geográficos de Portugal. Na verdade, conhecem-se bem os ecos da vanguarda italiana em Lisboa ${ }^{5}$. Mas está por esboçar uma perspectiva mais alargada e articulada do Futurismo, que avance pelo espaço geográfico da literatura e da recepção crítica, assinalando a multiplicidade da sua expressão, sobre o mapa.

Comecemos, pois, pelo início. A notícia do Manifesto de fundação do Futurismo é dada, em primeira mão, por um jornal do Porto, o Jornal de Notícias ${ }^{6}$. A ligação entre Paris e a cidade do Porto tem por elo mediador José Xavier de Carvalho Junior. Nascido em Lisboa em 1861, desloca-se para o Porto, onde trabalha como jornalista, até que, em 1886, parte para Paris na qualidade de correspondente de vários jornais portugueses e brasileiros, cidade onde morre em 1919.

$\mathrm{O}$ artigo, intitulado "Uma nova escola poética - o Futurismo", sai no Jornal de Notícias de 26 de Fevereiro de 1909, ou seja, poucos dias depois de o Manifesto de fundação do Futurismo ter sido publicado, em francês, por Le Figaro, mais precisamente, a 20 de Fevereiro, em simultâneo com a edição e distribuição de panfletos em italiano e em francês. Xavier de Carvalho apresenta o Futurismo nos seus aspectos gerais. Enquadra-o na sucessão de -ismos que vai do Decadentismo

Electa) e, sucessivamente, Chicago, Museum of Contemporary Art. Vd. supra, pp. 271-275.

${ }^{5}$ Valha por todos o reenvio para os textos de Nuno Júdice e Teolinda Gersão que acompanham a reedição de Portugal Futurista, Lisboa, Contexto, 1982.

${ }^{6}$ Este assunto foi tratado por Pedro da Silveira, que reedita os dois artigos de José Xavier de Carvalho, em “O que soubemos logo em 1909 do Futurismo”, Revista da Biblioteca Nacional, 1, 1, 1981, pp. 90-103. 
e do Simbolismo ao Satanismo, dando informações sobre o seu líder, o seu nome e o seu programa. Neste âmbito, são parafraseados dois passos do manifesto, onde a guerra é glorificada como única higiene do mundo e se advoga a destruição de museus e bibliotecas. O jornalista português é particularmente sensível à questão da violência e do belicismo, acompanhando o pulsar de uma Europa prestes a entrar em Guerra. Não adere, porém, ao seu programa genérico, o qual lhe merece críticas, em nome da moral e dos bons costumes, nem leva o manifesto muito a sério, classificando-o como um ror de disparates ao jeito de blague carnavalesca.

Mas o movimento devia ter assumido, de facto, algum significado, para Xavier de Carvalho, se na edição do Jornal de Notícias de 6 de Abril de 1909 volta ao assunto com uma notícia sobre "O Rei Bombance - o fiasco da peça de Marinetti", a que assistiu em Paris, no Théatre de l'oeuvre. Trata-se de uma tragédia satírica em que as personagens, que são alegorias de vícios, com o desespero da fome, se revoltam contra o Rei e fazem um banquete desmedido, o que lhe permite recuperar o poder. A peça marca uma ruptura decisiva, no panorama teatral de início de século, abrindo uma frente estética de reconhecido alcance. Contudo, o jornalista português pouco mais nela descortina do que um fiasco, uma chuchadeira, um desfile de excessos gastronómicos sem regras de teatro e uma brincadeira trocista, retomando um tópico já presente no artigo que anteriormente escrevera. Nesse sentido, ao colocar em destaque o sucesso de escândalo de Marinetti, comporta-se como se fosse o seu espectador ideal, para retomar a terminologia de Umberto Eco. Não deixa de apreciar a beleza dos cenários de Ranson, ou seja, Paul Ranson, um dos membros do grupo da vanguarda simbolista conhecida como Nabis, que contestou o impressionismo, desenvolvendo um estilo decorativo de linhas e figuras geométricas.

Apesar de não estar em condições de compreender a atitude vanguardista e a relação estabelecida com o público, 
José Xavier de Carvalho acompanha a novidade, dando-a a conhecer aos leitores do Jornal de Notícias.

A notícia sucessiva acerca do Futurismo, divulgada pela imprensa portuguesa, sai num jornal editado em S. Miguel, o Diário dos Açores, a 5 de Agosto do mesmo ano ${ }^{7}$. Segue critérios mais documentados, abrindo-se com uma nota de apresentação da nova escola literária, ao que se segue a tradução parcial do Manifesto de fundação do Futurismo, uma entrevista com Marinetti tirada da revista Comoedia e uma apreciação crítica, sob a epígrafe "Os escritores e a imprensa". Desta feita, o seu autor, Luís Francisco Rebelo Bicudo, é o mediador da linha que liga Ponta Delgada a Génova, de onde escreve. Nascido naquela cidade açoriana em 1884, no seio de uma família aristocrata, foi apoiante da República e estudou Direito em Coimbra, depois do que partiu para um grand tour europeu.

A tradução omite a parte inicial do manifesto, abrindo-se com os seus onze pontos programáticos. Talvez o passo suprimido, onde se conta a noite de vigília sob lâmpadas de mesquita e o desastre de automóvel de Marinetti, fosse considerado dissuasor ou entediante, isto caso Le Figaro fosse a fonte de Bicudo ${ }^{8}$. A própria tradução atenua algumas facetas mais radicais do original. Quanto à entrevista, incide em particular sobre aspectos de índole ideológica e de debate de ideias. Trata a relação entre plano individual e colectivo, a recepção por parte do público, e explicita as propostas essenciais do movimento, que era o que mais despertava a atenção, num momento em que tinha acabado de ser anunciado. $\mathrm{Na}$ parte final do artigo, Rebelo Bicudo traça uma visão de síntese dotada de relevante sentido crítico. As suas preocupações documentais são ilustradas pela consulta e referenciação de fontes, a partir da revista de Marinetti, Poesia. Enumera os

\footnotetext{
$7 \mathrm{Vd}$. ib., que reedita o artigo

8 Vd. supra, n. 1.
} 
seus colaboradores e faz uma resenha da imprensa estrangeira sobre o Futurismo, com base em informações nela contidas ${ }^{9}$. Bicudo percebe que, para além da simples condenação ou do simples apoio ao Futurismo, há que entender a profundidade de um movimento literário que esconde uma escola filosófica. Por conseguinte, põe de lado os comentários trocistas, destacando os intuitos de renovação e a vertente iconoclasta da vanguarda italiana. O seu cosmopolitismo fica patente no orgulho, traduzido logo no início do artigo, de o Diário dos Açores ser um dos primeiros jornais a apresentar, em Portugal, a nova escola. E, a terminar, empenhado em aproximar o universo açoriano da vanguarda europeia, estimula os poetas da sua terra a estabelecerem contactos com os futuristas.

Apesar do apelo de Bicudo, a passagem da recepção do Futurismo, do plano crítico, ao da recepção criativa, não foi, aparentemente, imediata. Os sucessivos sinais dessa recepção são de 1913, situam-se no âmbito programático, e vêm de um longínquo território colonial português, Nova Goa. O primeiro número da Revista da India abre-se com um "Manifesto", assinado por Paulino Dias, onde Marinetti é uma referência fundamental ${ }^{10}$. O periódico, que tem por subtítulo Mensal de Letras e Artes, saiu entre Junho de 1913 e Julho de 1914, tendo por directores Paulino Dias e Adolfo Costa.

9 Não menciona, no entanto, os poetas de língua portuguesa que nela participaram. Pelo que diz respeito ao poeta brasileiro Magalhães de Azeredo, vd. Sílvio Castro, "Carlos Magalhães de Azeredo e a Enquête internationale sur le vers libre de Marinetti”, El girador. Studi di letterature iberiche e ibero-americane offerti a Giuseppe Bellini, a cura di Giovanni Battista De Cesare e Silvana Serafin, Roma, Bulzoni, 1993, vol. 1, pp. 191-199. Também colaboram em Poesia E. Machado e António Nascimento de Mendonça.

${ }_{10}$ Vd. Sandra Bagno, "Il Futurismo a Goa e la Revista da Índia", Rosa dos Ventos. Atti del Convegno. Trenta anni di cultura di lingua portoghese a Padova e a Venezia, a cura di Sílvio Castro e Manuel Simões, Padova, Università di Padova, Sezione Portoghese dell'Istituto di Lingue e Letterature Romanze, 1994, pp. 89-101; e "O Futurismo libertário na Índia portuguesa”, Jornal de Letras, Artes e Ideias, 15, 640, 1995, pp. 26-27, que transcreve largos passos do "Manifesto". 
Os princípios programáticos da revista, ao serem transferidos, do domínio do editorial, para o do manifesto, enchem-se de um tom combativo. Paulino Dias começa por seguir o fio emancipador que vai da Aufklärung até ao início de século, operando um nivelamento universal e utópico que abarca Cristo, Tolstoi e Bacunine. Esse eclectismo culmina com uma exaltação da Renascença literária das nacionalidades que toma Marinetti como baluarte da argumentação lógica do "Manifesto". Ponto capital, é a energia de boxer com que o líder da vanguarda italiana combate o passadismo de um país antigo, o que mostra, segundo Paulino Dias, que as nações modernas são francamente futuristas. Depois de passar em resenha aspectos identitários, tipificados, de vários países, detém-se sobre a especificidade da Índia portuguesa, enquanto possível cruzamento entre Oriente e Ocidente donde brota o peito moço da Índia. Em seu entender, também o movimento de consciência nacional que aí se está a formar é uma reacção contra as forças atávicas e o misticismo absurdo.

Para compreender o interesse pelo Futurismo italiano, em função desta questão identitária, há que ter em linha de conta o movimento de afirmação da Índia portuguesa que se forma entre finais do século XIX e inícios do século XX. O jornalismo e a literatura foram duas das suas grandes frentes ${ }^{11}$. Ora, Paulino Dias e tantos dos colaboradores na Revista da Índia pertenciam a esse grupo de escritores e jornalistas indo-portugueses. Na verdade, a produção poética coligida nos vários números, de grande interesse para a intersecção entre culturas e literaturas, pouco ou nada tem de futurista. No entanto, a vanguarda italiana era conhecida de modo próximo, a ponto de, em 1913, já se dizer que o manifesto de 1909 fora publicado anos atrás. Aliás, o poeta indo-português António Nascimento Mendonça publicara, no número de

11 Vd. Vimalda Devi, Manuel de Seabra, A literatura indo-portuguesa, Lisboa, Junta de Investigação do Ultramar, 1971, 2 vols. 
1908-1909 de Poesia, uma composição dedicada a Marinetti, o que mostra existirem relações entre a vanguarda italiana e a vanguarda goesa que muito importaria estudar.

Nos anos de 1916 e de 1917, há a assinalar a presença de vários núcleos vanguardistas, entre Faro, a Figueira da Foz e Coimbra. Este fervilhar de ideias situa-se, de uma forma ou de outra, na senda das iniciativas levadas a cabo em Lisboa, além do mais, com a edição de Orpheu, o Manifesto Anti-Dantas, a sessão futurista no Teatro República, em que José de Almada Negreiros lê o Ultimatum futurista às gerações portuguesas do século XX, e o número único de Portugal Futurista, de 1917.

Comecemos por Faro, onde um grupo de vanguardistas se reuniu em torno do jornal O Heraldo e organizou uma exposição $^{12}$. Em Maio de 1917, esteve patente, nessa mesma cidade, uma mostra, cujo catálogo se intitula Futurismo, na qual participaram Mirly, Zarna e Rodrigue e Carlos Porfirio. Pintor de grande mérito, cuja obra permanecerá ligada à estética futurista, e que, posteriormente, também se veio a dedicar ao cinema. Porfírio era natural de Faro, mas estava ligado, à semelhança de outros membros do grupo, ao núcleo de Lisboa, tendo sido fundador e director do Portugal Futurista. Recorde-se que, nas páginas de O Heraldo, Almada publicou Litoral, Fernando Pessoa $A$ casa branca nau preta, poema que depois viria a ser atribuído a Álvaro de Campos, e Mário de Sá Carneiro, Além.

A 5 de Novembro de 1916, é inaugurada uma nova secção do jornal, chamada Gente Nova, e a 4 de Fevereiro de 1917 uma outra, intitulada Futurismo. Ambas se mantêm até à última edição do periódico, que saiu a 29 de Agosto de 1917. Os colaboradores assinam sob pseudónimo. Horácio ou O’Racio é João Rosado; Nesso, Carlos Porfírio; Raul Marques Carneiro, A. Queiroz; Kernok é Leyster Franco, o

12 Em Poesia futurista. Faro 1916/1917, selecção e prefácio de Nuno Júdice, Lisboa, A Regra do Jogo, 1981, este crítico estuda e reedita parte dessa produção. 
próprio director do jornal; Naissance é António de Nascimento. Traços poéticos comuns e remissões mútuas mostram o espírito de grupo que os unia. As reacções que suscitam são oportunamente aproveitadas para explicitar e defender o seu vanguardismo. Numa carta de apoio, com data de 15 de Julho de 1917, assinada pelos representantes do comité futurista, ou seja, Almada Negreiros e Santa Rita-Pintor, agradece-se e exalta-se o seu empenho futurista. Uma misteriosa Miss Edith dirige-se ao jornal, deslumbrada pela incendiária lucilação da grande Arte Futurista.

A linguagem plástica dos poemas actualiza a revolução tipográfica advogada por Marinetti, com relevo para as composições assinadas por Kernoc e Carlos Porfirio, que exploram a relação entre imagem e texto verbal com particular elegância. Concomitantemente, é superada a velha sintaxe de Homero, com uso recorrente do verso livre, de duplas de substantivos e da técnica das palavras em liberdade. O sentido de dispersão é trabalhado a partir da técnica do fragmento e do jogo de sensações, e no tratamento do tema da viagem lêem-se ecos da poesia de Orpheu. A estética da máquina e a violência não são, porém, eleitas objecto de exaltação.

Por esses mesmos anos, estuda em Coimbra, onde se formou em Direito, o exótico e popular Francisco Levita (1894-1924) ${ }^{13}$. Conhecia bem o programa futurista e encontrava-se enquadrado na atmosfera coimbrã. O seu nome ficou gravado nas memórias de estudantes e a sua poesia de vanguarda teve um impacto tal, que foi parodiada pelas revistas da cidade. Certa ocasião, alugou um automóvel e dirigiu-se, com alguns amigos, para o Palace do Bussaco, onde a presença de estudantes escandalizou uma clientela seleccionada. Encomendaram uma ementa digna de verda-

13 Vd. Rita Marnoto, Francisco Levita, Negreiros-Dantas [....] Coimbra manifesto 1925, Lisboa, Fenda, 2009, onde se reproduz, em facsímile, o manifesto de 1916 e outros textos de Levita. 
deiros futuristas: galinha com chocolate, omelete de pêssego e, a acompanhar, champanhe francês. Levita também desenha, adoptando aquele geometrismo linear que cedo começou a ser usado em Coimbra, na caricatura.

Além do livro I assim... Poemas [....] seguidos do Elogio do I e da tragédia em 1 acto Amor! Amor!, assinale-se o manifesto Negreiros - Dantas. Uma página para a história da literatura portuguesa, ambos de 1916, este último em polémica com Almada Negreiros, que talvez tivesse conhecido na sua fugaz passagem por Coimbra. A desafiar Almada, foram tantos, a desafiá-lo como vanguardista, Francisco Levita teria sido um dos poucos. Conclui que, alguém que se preocupa com Júlio Dantas, é um Dantas n. ${ }^{\circ} 2$.

De Coimbra, passemos à Figueira da Foz, em cujo ambiente literário era cultivada poesia simbolista e decadentista. Fernando Pessoa, em apontamentos onde traça um quadro alargado do sensacionismo, chama a atenção para a revista $O$ Fauno, com um número único que saiu na Figueira em $1917^{14}$. Foi seu director Manuel de Sousa e seu editor Raimundo Esteves.

No entanto, um outro grupo há a assinalar, no seio do qual se destacam António Mariano da Cunha Goulart, Luís Joaquim Pinto e António Correia Pinto d'Almeida. O primeiro estudou Direito em Coimbra, nos anos de 1915-1916 e 1916-1917. Pinto d'Almeida, que assinou várias obras com o pseudónimo de António Amargo, escreveu, em colaboração, com Goulart, um livro de Sonetos mínero-metálicos, de 1917, cujo autor se identifica como António Doce Amargo ${ }^{15}$.

14 Vd. Gianluca Miraglia, "Os novos da Figueira da Foz", Foro das Letras, 13-14, 2006, pp. 99-104.

15 Pensou-se que se tratasse de um único poeta, chamado António, até pela forma como é graficamente representado o nome do autor dos Sonetos mínerometálicos (Coimbra, França Amado, 1917), com uso de uma chaveta, mas a dedicatória do exemplar existente na Biblioteca Municipal Pedro Fernandes Tomás, da Figueira da Foz, com a cota 82-1AMA, vem esclarecer esta questão. 
Reúne dezanove sonetos em que sentimentos e emoções são expressos através de referências a materiais metálicos, compostos, pedras, ou fórmulas químicas. Tem por epígrafe Ao Sr. Júlio Dantas, médico em literatura e literato em medicina, ourives mimoso da forma e supremo joalheiro do ritmo.

$\mathrm{O}$ facto de Goulart ter estudado Direito em Coimbra, a atitude destes vanguardistas perante Júlio Dantas e o fascínio por certas matérias da vida moderna, sobre um pano de fundo onde avulta a figura do filósofo figueirense Joaquim de Carvalho, levam a crer que estes futuristas da Figueira da Foz giravam na órbita de Francisco Levita.

Na década de 1920, a geografia do Futurismo/s português assinala dois núcleos, um em Ílhavo, outro em Coimbra, ao qual cabe um importante papel, na história da literatura portuguesa do século XX. Têm por elo de ligação o artista plástico, médico e escritor, João Carlos Celestino Gomes.

Chegaram até nós vagas notícias de um grupo de vanguarda de Ílhavo, designado como plêiade ilhavense ${ }^{16}$. Levava à cena espectáculos no Teatro do Novos, nessa vila, e no teatro da Vista Alegre. No início da década, Celestino Gomes edita alguns textos de pequena dimensão, caracterizados por um tom expressionista, turbulento e vital, que contêm, em gérmen, a paleta daquele que viria a traduzir Il trionfo della morte de Gabriele D’Annunzio. É em Ílhavo que, em 1924, publica um panfleto intitulado Sobre o atavismo, onde expõe a lei da hereditariedade, mas nas suas repercussões negativas, tendo em linha de conta como, por essa via, se perpetuam vícios e taras que impedem a selecção dos inúteis. O darwinismo erige-se, pois, em vínculo a um passado, cujo atavismo impede a plenitude do futuro. Esta posição poderá ser confrontada com a lei de Malthus da sensibilidade, no Ultimatum

$16 \mathrm{Vd}$. o testemunho de Guilhermino Ramalheira, no volume In memoriam do Dr. João Carlos Celestino Gomes, 1899-1960, Aveiro, Coimbra, Arquivo do Distrito de Aveiro, 1962, em particular p. 63. 
de Álvaro de Campos publicado em Portugal Futurista, embora a conceptualização e a exposição de Celestino Gomes tomem outro sentido ${ }^{17}$. O texto expositivo obedece a uma formulação linguística tradicional. Inicia-se, porém, com uma súmula escrita em estilo futurista, como se de um guião se tratasse, que prescinde de nexos sintácticos e usa sinais matemáticos.

Por sua vez, "O movimento futurista de Coimbra" é o título do artigo, editado pelo Diário de Lisboa, a 13 de Março de 1925, em que se anuncia a revolução artística que está a ser preparada nessa $\operatorname{cidade}^{18}$. O jornalista apresenta o seu líder, Mário Coutinho, no seu quarto da Alta, rodeado por manifestos e obras plásticas de vanguarda, e tendo sobre a mesa de trabalho um manifesto de Marinetti. Trata-se, pois, de um grupo que conhece bem o programa dos futuristas italianos.

Uma das peças fundamentais da sua actividade de agitação foi o panfleto intitulado Coimbra manifesto 1925, que se inicia com duas citações de Marinetti. Divide-se em quatro partes, cada uma das quais é assinada por um pseudónimo, Óscar, ou seja, Mário Coutinho, natural de Caldas da Rainha, estudante de Medicina; Pereira São-Pedro (Pintor), o já referido João Carlos Celestino Gomes; Tristão de Teive, Abel Almada, natural do Funchal, também ele estudante de Medicina; e Príncipe de Judá, António de Navarro, oriundo

17 Conforme nota José António Bandeirinha, enquanto o darwinismo aviva a consciência de que o homem é descendente do macaco, o Futurismo incita, programaticamente, à fuga desse passado através da velocidade e do dinamismo: "o homem apanha comboios a vapor, depois a gasóleo, depois eléctricos, depois aviões a jacto, transportes cada vez mais rápidos para fugir à condição de descendência do macaco. Quanto mais rápido viajar, mais distante fica essa fatal constatação, quanto mais rápido se fizer transportar, mais longe caminhou na fuga dessas origens e mais honrosas se tornam as diferenças relativas a essa condição ancestral", "Violentia Velox Visio. Leituras em movimento", NU, 28, 2009, p. 13.

18 Rita Marnoto, cit., onde é transcrito este e outros textos relacionados com o movimento, e se reproduz o manifesto de 1925. 
de Nelas, que frequentava a Faculdade de Direito. O folheto associa a arte de vanguarda à clarividência tipográfica. A divisão em duas colunas, com interposição de barras a toda a largura e garrafais, exige o domínio de técnicas compositivas muito específicas. Aliás, o seu grafismo é semelhante ao da revista Lacerba. Foi também organizada uma conferência no Teatro Sousa Bastos, proferida por António de Navarro, que acabou com um banho de agulheta. Intitulava-se Sol, que era, igualmente, o título da revista que se propunham editar. Sol foi uma palavra-chave para os futuristas italianos. Servia de contraponto à lua e ao luar, símbolos do passadismo e alvo primordial do panfleto Uccidiamo il chiaro di luna!, publicado dois meses depois do Manifesto de fundação do Futurismo.

O livrinho Guarda-sol. Exortação à mocidade futurista precedida dum prefácio às frontarias. Abaixo a cor! Bendita a lua!, um octógono que abre da esquerda para a direita, publicado em Coimbra no mesmo ano, sob o pseudónimo de Humsilfer, e dedicado a Almada Negreiros, é uma paródia do manifesto de Levita e do Coimbra manifesto 1925, o que mostra que eram situados numa linha de continuidade ${ }^{19}$. O seu autor será, no entender de quem escreve, Humberto da Silveira Pinto, estudante de Direito e colega de António de Navarro, que nele é referido.

A importância do movimento futurista de Coimbra, para a história da literatura portuguesa do século XX, prende-se com a criação da revista Presença. Tratou-se, na verdade, do trampolim que permitiu ultrapassar um impasse, àquele núcleo de intelectuais que procurava outro rumo, mas que carecia de uma força canalizadora. Constitui, por isso, um precedente fundamental da Presença. É em função do ímpeto propulsor desse grupo de vanguarda que melhor se pode

19 Fez-lhe uma fugaz referência, M. Maiani, Aspectos do futurismo na obra de Fernando Pessoa, tesi di laurea, Università degli Studi di Venezia, Facoltà di Lingue e Letterature Straniere, 1991-1992, p. 45. 
compreender como, da revista Byzancio, uma publicação ligada ao simbolismo e ao decadentismo, e Triptico, mais virada para a cultura europeia e para as artes, se passa a uma iniciativa editorial com a abertura internacional e o lastro artístico da Presença.

Este panorama, desenhado a traços largos, dá uma imagem muito vária e articulada do Futurismo/s português. Foram apresentados os seus pontos nodais, mas tantos outros haveria, eventualmente, a acrescentar. Mereceriam investigações específicas, que recuperassem materiais que jazem esquecidos em arquivos públicos ou em fundos de particulares, sob risco de extravio.

Do quadro aqui exposto, resulta, no seu conjunto, uma malha abrangente, que de Ílhavo se estende à Índia colonial portuguesa, passando pelos Açores. Se as modalidades de recepção do Futurismo se revelam bastante diversificadas, articulações de substrato e horizontes de actuação conferem uma significativa variedade aos seus resultados. Os materiais coligidos dizem respeito ao jornalismo, ao comentário crítico, ao enunciado programático, à criação poética, à performance, ao plano dos costumes, ao grafismo ou às artes-plásticas. O Futurismo é a plataforma a partir da qual se exprimem aspirações identitárias, reservas evolucionistas ou grandes projectos culturais, como é o caso da Presença, numa multiplicidade de facetas que revela bem o potencial de irradiação do movimento de Marinetti. 